\title{
Maternal insecurity and failure to thrive in Asian children
}

\author{
T R FENTON, ${ }^{*}$ R BHAT, $\dagger$ A DAVIES, ${ }^{*}$ AND R WEST $*$ \\ Departments of *Paediatrics and †Child Psychiatry, St George's Hospital Medical School, London
}

SUMmaRY Four Asian babies were investigated because they failed to thrive. In all four cases the failure to thrive was a result of the mother's social isolation and inability to communicate, and to the father's refusal to accept that there was a problem in the family.

Non-organic (emotional) failure to thrive is common in infancy. ${ }^{12}$ The children may have a characteristic watchful posture, but often the only abnormal findings are that they are underweight for height and bone age is retarded. ${ }^{3}$ They may also show retarded language development and social adaptive behaviour. $^{3}$ Abnormal social interaction between the parents, and between the parents and their child, may also be observed during the interview. ${ }^{3}$ The common finding is an inadequate intake of calories, ${ }^{3-5}$ the reasons for which are complex. A small group of children simply refuse food ${ }^{6}$ but most have obvious family problems. Social deprivation, maternal depression, and inadequate parenting skills are common contributory factors in the psychopathology in these families. ${ }^{67}$

It has been suggested that the child may contribute to the disturbed family relationships, ${ }^{5}$ and a subgroup of children has been described ${ }^{8}$ who from the age of 6 months actually resist the mother's attempt to feed them, thereby exacerbating the mother's inability to handle the child appropriately and leading to a separation disorder. We report four Asian children who, though similar to this last group, show differences caused by cultural and social circumstances.

\section{Case reports}

CASE 1

This girl was well until she was 3 months old when weaning was attempted. She was initially breast fed, and had been changed uneventfully to formula feed when she was 2 months old. When infant foods were introduced at the age of 6 months she started vomiting and refusing solid food. Despite dietary advice her weight gain continued to be poor. When she was referred at the age of 1 year there were no abnormal physical findings apart from some wasting. All investigations including histological examination of a jejunal biopsy specimen were normal.

The family history is summarised in the table. Her mother had given birth to an anencephalic infant shortly after she arrived in England two years earlier, and the patient was conceived within a few months of this baby's death. The family accommodation was poor and cramped; the mother spoke little English and was socially isolated. Furthermore, at weaning the mother had been unable to obtain her traditional foods and had relied on strained puddings. After psychiatric treatment, the mother was able to talk about her isolation and the development of social phobia, and acknowledge the family's grief over-and need to mourn - the dead baby. With the aid of the social services transfer to more suitable accommodation was arranged. The mother gained sufficient confidence to talk about her grief, she took appropriate dietary advice, and joined English classes. This was accompanied by a marked improvement in the child's weight gain.

\section{CASE 2}

This girl breast fed normally until she was 5 months old when her mother became unsure of her milk supply and the baby refused to accept any other milk or solids. She subsequently failed to thrive but no cause for this could be found despite extensive investigation. She was the first child of the father's second marriage. The mother had been anxious about her capacity to bear children because of a miscarriage two years previously. The mother, who seemed withdrawn and depressed, was socially isolated and resentful about the lack of support she received from the father. Her anxieties, coupled with the patient's faddiness about food, led to a cycle of food refusal and comforting at the breast. 
Table Family histories

\begin{tabular}{|c|c|c|c|c|}
\hline & \multicolumn{4}{|l|}{ Case No } \\
\hline & 1 & 2 & 3 & 4 \\
\hline Country of origin of parents: & Bangladesh & Pakistan & Bangladesh & Pakistan \\
\hline \multirow[t]{4}{*}{ Father: } & 48 & 47 & 41 & 39 \\
\hline & Waiter & Banker & Banker & Banker \\
\hline & & $\begin{array}{l}\text { First wife } \\
\text { (mother's sister) } \\
\text { died of typhoid }\end{array}$ & $\begin{array}{l}\text { Divorced first wife after } \\
\text { her mental breakdown }\end{array}$ & \\
\hline & Arrived England 1962 & Arrived England 1969 & Arrived England 1969 & Arrived England 1970 \\
\hline \multirow[t]{4}{*}{ Mother: } & 33 & 32 & 26 & 22 \\
\hline & Housewife & Housewife (teacher) & Housewife & Housewife (teacher) \\
\hline & Arrived England 1983 & Arrived England 1978 & Arrived England 1983 & Arrived England 1981 \\
\hline & Depressed & Depressed & Depressed & Depressed \\
\hline \multirow[t]{5}{*}{ Mother's obstetric history: } & 1973 Boy & 1981 Miscarriage & No previous pregnancies & No previous pregnancies \\
\hline & 1975 Miscarriage & 1983 Girl propositus & 1983 Boy propositus & 1983 Girl propositus \\
\hline & 1982 Boy & & & \\
\hline & $\begin{array}{l}1983 \text { Girl anencephalic } \\
\text { at } 34 \text { weeks' gestation }\end{array}$ & & & \\
\hline & 1985 Girl propositus & & & \\
\hline Social circumstances: & $\begin{array}{l}\text { Live in two rooms } \\
\text { above restaurant }\end{array}$ & Good & Good & Good \\
\hline
\end{tabular}

After repeated home visits by a child psychiatrist the mother eventually admitted her feelings of inadequacy as a mother, and the stress of being a second wife and stepmother.

The psychiatrist's ability to speak in the mother's native language was a great help, but was even more important in setting appropriate tasks with mother and child as part of a simple behavioural programme aimed at ensuring mother's full attention to the child at meal times and providing separate periods when the mother would take part with the child in activities other than feeding (for example, playing and story telling). This led to a gradual improvement in the relationship between mother and child and a steady but slow improvement in the child's weight gain over the course of one year.

CASE 3

This child progressed normally until the age of 5 months when, at the first attempt at weaning, he started vomiting all solids. He was investigated when he was 6 months old for failure to thrive, and no cause was found. A period of excluding cows' milk from his diet made no difference to his symptoms, and breast milk continued to be the main component of his diet until after he was 9 months old. Continuing weight loss prompted a further admission to hospital when he was 18 months old. Investigations including histological examination of a jejunal biopsy specimen were normal (apart from a mild dietary iron deficiency anaemia). With previous experience in mind, the family was referred to a child psychiatrist.

The father's first marriage had ended in divorce. The first wife had become depressed after the death of their first child at 14 months of congenital heart disease. The patient's mother, who spoke little English, had only recently arrived from Bangladesh and was socially isolated and depressed. Things were made worse by the feeling of inadequacy the mother had when she compared herself with her flamboyant westernised sister who lived nearby.

The patient ignored all food put before him and tried to make his mother play and tell stories. Psychiatric treatment concentrated on allowing his mother to explore her feelings about the stresses in the perinatal phase and the problems of being a second wife, and also understanding her own sibling rivalry with her sister. Firm dietary advice and support, including the mother making contact with other mothers at a local play group, was followed by satisfactory weight gain (figure).

\section{CASE 4}

This boy, who was born at 37 weeks' gestation and was small for gestational age, progressed well at first showing good catch up growth on bottle feeding. He started vomiting and refusing solid foods at weaning. When he was 8 months old full investigation failed to show any cause for his failure to thrive.

Like the other mothers, this patient's mother had arrived in England long after her husband and with 

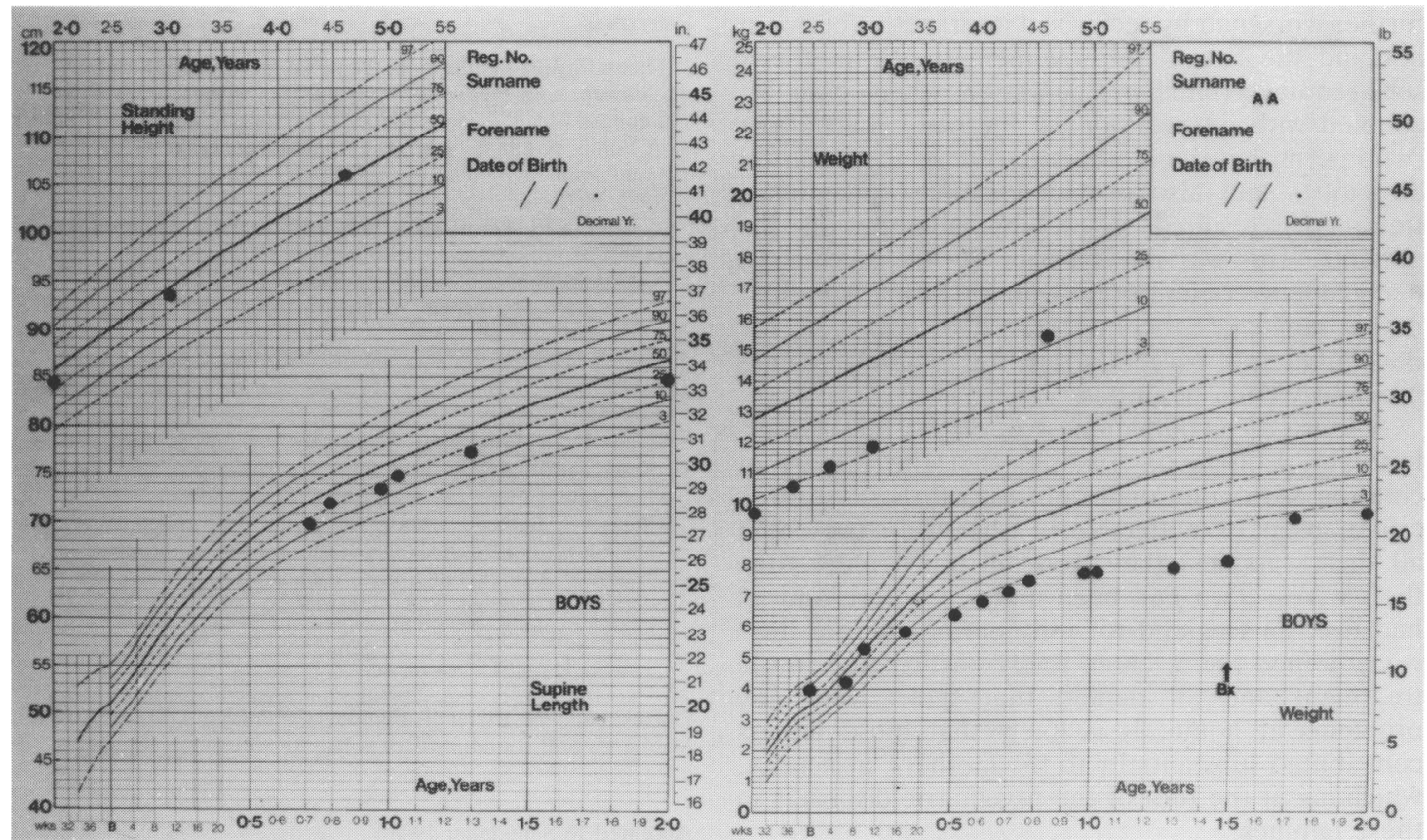

Fig 1 Growth chart of case 3. The weight increased at the time of psychiatric treatment after admission to hospital for jejunal biopsy $(B x)$.

her lack of English had become isolated and depressed (in contrast with Pakistan where she had been a teacher with a full social life). Despite this, it took several home visits by a child psychiatrist to gain the mother's confidence. The mother's inexperience and isolation had resulted in punitive attempts to force the child to eat. Introduction of a behaviour modification programme, and encouraging the mother to talk about her marital dificulties, loss of occupation, and social isolation as well as widening her social contacts by enrolling the child in a play group, resulted in relief of the mother's depression and the child gained weight.

\section{Discussion}

These four patients show several similarities. All developed pronounced failure to thrive at the time of weaning, their weights falling from on or above the third centile to well below the third centile. They continued to grow appropriately, however, being between the third and 50th centiles for height. All investigations, which included full blood count, estimation of urea and electrolyte concentrations, clotting studies, liver function tests, estimation of immunoglobulin concentrations, midstream urine culture, and examination of a jejunal biopsy specimen, were normal. All four mothers experienced difficulty with weaning, and breast milk remained the mainstay of nutrition during the first year for two patients. The lack of advice normally provided by the extended family contributed to their problems; this was further compounded by difficulties in finding suitable weaning preparations that did not contain substances that were unacceptable because of their religious beliefs (for example, non-halal meat, animal fat, and rennet that are found in such infant foods as lamb and chicken dinners, and cheese savouries). Dietary assessment showed that all had diets with adequate protein content but they were low in calories, vitamin $\mathrm{C}$, and iron. All patients had low serum iron concentrations with normal iron binding capacity, and three were mildly anaemic (haemoglobin concentrations 104-108 g/l). None, however, responded to iron. Unlike many children who fail to thrive, these patients were bright and happy and developing normally, but were intensely attached to their mothers.

The mothers had all lost self confidence. They had all recently arrived in England and felt isolated and insecure. In two cases, the mother's previous child had died and in one there had been a preceding miscarriage. The mother's poor self image was 
further worsened by reciprocal interactions between her and the baby. ${ }^{5}$ Improvement in the mother's social contacts (and home conditions when possible), coupled with intervention by the child psychiatrist (who permitted the mothers to discuss their marital difficulties and also provided simple behavioural treatment) resulted in weight gain by all the patients. This was made easier by the psychiatrist being able to communicate with the mothers in their native language, the importance of which in the development of psychotherapeutic relationships has previously been described. ${ }^{9}$

A sense of incompleteness pervades these cases, however. Others have noted that the fathers of children with emotional failure to thrive are often either absent or ineffective. ${ }^{2}$ Fathers were present in all these families; they were all much older than their wives. Two had been married before and all had lived in England for long periods before their wives joined them. None really participated in the treatment and all denied that there were any problems at home. It is likely that these fathers contributed substantially to the mothers' insecurity, which lay at the root of the psychiatric disorders in these families.
References

${ }^{1}$ Hannaway PJ. Failure to thrive. A study of 100 infants and children. Clin Pediatr 1970;9:96-9.

2 Leonard FM, Rhymes JP, Solnit AJ. Failure to thrive in infants. A family problem. Am J Dis Child 1966;111:600-12.

${ }^{3}$ Goldbloom RB. Failure to thrive. Pediatr Clin North Am 1982;29:151-66.

${ }^{4}$ Whitten CF, Pettit MG, Finschoff J. Evidence that growth failure from maternal deprivation is secondary to undereating. JAMA 1969;209:1675-82.

5 Skuse DH. Non organic failure to thrive. A reappraisal. Arch Dis Child 1985;60:173-8.

6 Graham P. Development and its disorders. Child psychiatry-a developmental approach. Oxford: Oxford University Press, 1986:54-63.

${ }^{7}$ Evans SL, Reinhardt JB, Succop RA. Failure to thrive. A study of 45 children and their families. Journal of the American Academy of Child Psychiatry 1972;11:440-57.

${ }^{8}$ Chatoor I, Egan J. Non organic failure to thrive and dwarfism due to food refusal: a separation disorder. Journal of the American Academy of Child Psychiatry 1983;22:294-301.

9 Stern J. Language and authority in psychotherapy. Group Analysis 1987;3:221-35.

Correspondence to Dr T Fenton, Greenwich District Hospital, Vanburgh Hill, London SE10 9HE.

Accepted 18 September 1988 